\title{
Stokes-Adams Syndrome
}

National Cancer Institute

\section{Source}

National Cancer Institute. Stokes-Adams Syndrome. NCI Thesaurus. Code C79765.

An episode of sudden and transient loss of consciousness sometimes associated with seizures. It is caused by a sudden decrease of the cardiac output that results from a sudden cardiac dysrhythmia. Typically patients develop an initial pallor, followed by facial flush during recovery. 